\title{
The Relationship between Life Stress and Breastfeeding Outcomes among Low-Income Mothers
}

\author{
Ann M. Dozier, ${ }^{1}$ Alice Nelson, ${ }^{1}$ and Elizabeth Brownell ${ }^{2}$ \\ ${ }^{1}$ Department of Public Health Sciences, University of Rochester, 265 Crittenden Boulevard., CU 420644, Rochester, \\ NY 14642-0644, USA \\ ${ }^{2}$ Department of Research, Connecticut Children's Medical Center, 282 Washington Street, Hartford, CT 06106, USA
}

Correspondence should be addressed to Ann M. Dozier, ann_dozier@urmc.rochester.edu

Received 31 August 2012; Revised 12 December 2012; Accepted 12 December 2012

Academic Editor: Katrin S. Kohl

Copyright () 2012 Ann M. Dozier et al. This is an open access article distributed under the Creative Commons Attribution License, which permits unrestricted use, distribution, and reproduction in any medium, provided the original work is properly cited.

\begin{abstract}
Stressful life events during pregnancy negatively affect maternal and infant outcomes including breastfeeding initiation. Their impact on breastfeeding duration is uncertain. Given breastfeeding's important health benefits we analyzed stressful life event types and cessation of any and exclusive breastfeeding by 4 and 13 weeks. Methods. We collected self-administered survey data at 5-7 months postpartum from over 700 primarily urban low-income US mothers. Data covered prepregnancy, prenatal, and postpartum periods including 14 stressful life events (categorized into financial, emotional, partner-associated, traumatic). Analyses included only mothers initiating breastfeeding $(n=341)$. Logistic regressions controlled for maternal characteristics including a breastfeeding plan. Results. All four stress categories were associated with shorter duration of any and exclusive breastfeeding. In the adjusted models, statistically significant relationships remained for financial stress (4 weeks cessation of any breastfeeding duration) and traumatic stress (13 weeks exclusive breastfeeding cessation). Controlling for stress, a longer breastfeeding plan was significantly associated with a shorter breastfeeding duration (all models) as was depression during pregnancy and current smoking (several models). Conclusions. Among low-income women, impact of stressful life events on cessation of breastfeeding may differ by stress type and interfere with achievement of breastfeeding goal. Among these stressed mothers, breastfeeding may serve as a coping mechanism.
\end{abstract}

\section{Introduction}

Optimal breastfeeding duration and exclusivity practices contribute to significant short- and long-term health benefits for both mother and baby $[1,2]$. Current professional associations, including the World Health Organization recommend exclusive breastfeeding for 6 months and continued breastfeeding for at least a year [3,4]. In the USA, efforts by professional, government, and health and human service organizations to increase breastfeeding rates resulted in increasing initiation rates $[5,6]$. Duration and exclusivity remain well below national goals, especially among lowincome mothers [7].

Numerous factors influence breastfeeding outcomes from institutional practices to individual characteristics and actions [8-10]. The latter include demographic and maternal factors such as maternal race/ethnicity (non-white and/or Hispanic) [11], less education [12], elevated prepregnancy
Body Mass Index (BMI) [13], language (English speaking) [14], and younger age [11], all of which are associated with early cessation of any and exclusive breastfeeding in the USA. Other known factors linked with early cessation include: poor sense of breastfeeding self-efficacy [15], smoking [16, 17], alcohol use [18], maternal depression [19, 20], and not having a prenatal breastfeeding plan $[18,21]$. Of note, lowincome mothers are more likely to experience several of these factors, possibly contributing to their earlier cessation of breastfeeding.

The extent to which mothers experience stressful life events and how these may be related to breastfeeding outcomes is less well understood. Stressful life events known to be associated with other negative or adverse perinatal outcomes include small for gestational age infants [22], gestational diabetes [23], increased risk of physical abuse [24], low birth weight and preterm birth [25], behavior problems for the infant later in life [26], and maternal depression 
$[27,28]$. Research describing associations between stressful life events and breastfeeding cessation is limited. For example, within the maternal depression and breastfeeding literature, stressful life events are typically only used as an adjusted factor and not a primary exposure [27]. Additionally, most studies are not specific to low-income women.

To our knowledge, only one study examined whether stressful life events during pregnancy influenced breastfeeding rates [29]. Stress in that study was quantified as a total stress score and showed that independent of maternal characteristics more stressful life events were significantly associated with earlier breastfeeding cessation. Given that stress is a complex phenomenon, a different approach may be warranted such as the one developed by Ahluwalia et al. (2001). Their methodology categorized stressful life events into four types (financial, emotional, traumatic, and partner associated) [22]. We chose this methodology instead of using a total life stress score. The latter, by weighting each event the same, assumes that each event is equivalent, which may not be the case. Further we were interested in observing how different types of stressful life events were associated with breastfeeding outcomes.

The purpose of this analysis was to examine the association between four types of stressful life events and breastfeeding outcomes (cessation of any and exclusive breastfeeding) among low-income mothers who initiated breastfeeding.

\section{Methods}

2.1. Setting. Mothers in this study resided in an upstate New York county, with a major metropolitan city and around 8000 births annually, of which approximately $40 \%$ occur to low-income mothers. We defined low-income as mothers prenatally enrolled in a food assistance program (Women's, Infants and Children's Supplemental Nutrition Program, WIC) and/or with deliveries paid for by publically funded health insurance programs (i.e., Medicaid). Four urban pediatric and one family medicine practice serving primarily low-income clientele assisted with survey distribution.

2.2. Sample. Eligible mothers were at least 5 months postdelivery of a live infant with residence in the county. Other than mothers' name and address no other demographic or contact information was provided by the practices about the mothers or index infants.

2.3. Data Collection. Participating practices identified all eligible mothers and provided electronic files with contact names and addresses. Survey distribution occurred through mailings to all mothers with usable addresses. The first mailing occurred between 5 and 7 months postpartum. Followup was restricted to a second mailing at 3 weeks. Telephone numbers were not provided so other types of followup were not possible. To incentivize participation, respondents were eligible to participate in a raffle.

2.4. Survey Instrument. The "You and Your Baby" Survey (YYBS) gathered surveillance data from mothers. In addition to demographics, the YYBS captured prepregnancy, prenatal, and postpartum information, using items primarily from the US Centers for Disease Control's Pregnancy Risk Assessment Monitoring System (version 6) [30] and items used in the primary author's previous surveys.

Following the first year of distribution, the YYBS included additional questions such as an adapted version of the Wagnild and Young's resiliency scale (16 items) [31, 32] and the "Moods and Feelings During Pregnancy Life Events Self-Evaluation" scale (33 events) [28]. The final survey for year two included 83 questions. Surveys were mailed with a cover letter and stamped self-addressed return envelope.

2.5. Stress Categories. The "Moods and Feelings during Pregnancy Life Events Self Evaluation" scale started with the question "Did any of these things happen during your pregnancy or in the first month of your baby's life?" Each of the 33 events listed included three responses: "No," "Yes, affected me a little," or "Yes, affected me a lot." Using a previously published methodology [22], 14 of the 33 events served as the basis to create four stress categories: partnerassociated (three items: separated from husband/partner, argued with husband/partner more often, husband/partner said he did not want pregnancy), traumatic (five items: stayed in a shelter or needed emergency shelter, physical fights with partner/husband or someone else, husband/partner had legal trouble and/or went to jail, mother had legal trouble and/or went to jail, someone very close had a problem with drinking or drugs), financial (two items: big problems with money, moved to a new address), and emotional (four items: family member had serious accident/illness, husband/partner had serious accident/illness, husband/partner died, friend/relative died). Respondents were classified as exposed if they responded "Yes" to any questions contained within each stress type.

2.6. Breastfeeding Outcomes. Mothers reported if they were currently breastfeeding and if not when they stopped (based on infant age). This information was used to calculate if the mother was still breastfeeding at 4 and 13 weeks (yes/no). Mothers also reported if and when the baby was introduced to formula, other liquids cereal, or solid foods. Using this information, exclusive breastfeeding duration was calculated at 4 and 13 weeks (yes/no) with exclusivity being defined as the infant receiving only breast milk and no other liquid or solid food.

2.7. Analyses. We conducted an exploratory analysis using bivariate analyses and multivariable logistic regression models utilizing mothers who initiated breastfeeding that completed the modified survey. We first analyzed the crude relationship between each of the 4 types of stress categories and cessation of any or exclusive breastfeeding (at 4 and 13 weeks). Final regression models included the exposure (one of the stress categories) and maternal variables identified through previous breastfeeding research: demographics including maternal age, race, language, education, and 
TABLE 1: Maternal characteristics.

\begin{tabular}{|c|c|}
\hline & $\begin{array}{c}n(\%) \\
n=341\end{array}$ \\
\hline \multicolumn{2}{|l|}{ Age } \\
\hline$n$, Mean & $325,26.3$ \\
\hline [Minimum-Maximum] & {$[14.0-45.0]$} \\
\hline \multicolumn{2}{|l|}{ Race $^{\mathrm{a}}$} \\
\hline White & $87(26.1)$ \\
\hline Black & $132(39.6)$ \\
\hline Hispanic & $84(25.2)$ \\
\hline Mixed and other & $30(9.0)$ \\
\hline \multicolumn{2}{|l|}{ Language spoken at home } \\
\hline English only & $238(70.6)$ \\
\hline English and Spanish & $56(16.6)$ \\
\hline Spanish or other only & $22(6.5)$ \\
\hline Other bi-multi-lingual & $21(6.2)$ \\
\hline \multicolumn{2}{|l|}{ Education $^{\mathrm{a}}$} \\
\hline$<$ High school & $56(16.4)$ \\
\hline$\geq$ High school & $254(74.5)$ \\
\hline Unknown & $31(9.1)$ \\
\hline \multicolumn{2}{|l|}{ Inner-City residence ${ }^{b}$} \\
\hline Yes & $220(64.5)$ \\
\hline \multicolumn{2}{|l|}{ BF Plan ${ }^{\mathrm{a}}$} \\
\hline $\begin{array}{l}\text { Less than } 3 \\
\text { months/none }\end{array}$ & $149(44.1)$ \\
\hline 4+ Months & $189(55.9)$ \\
\hline \multicolumn{2}{|l|}{ Parity and BF } \\
\hline First baby & $157(46.0)$ \\
\hline $\begin{array}{l}\text { Breastfed prior } \\
\text { Infant-Yes }\end{array}$ & $148(43.4)$ \\
\hline $\begin{array}{l}\text { Breastfed prior } \\
\text { Infant-No }\end{array}$ & $36(10.6)$ \\
\hline \multicolumn{2}{|l|}{$\begin{array}{l}\text { Self-Reported depression } \\
\text { during or right after most } \\
\text { recent pregnancy }\end{array}$} \\
\hline Yes & $90(26.4)$ \\
\hline \multicolumn{2}{|l|}{ Prepregnancy BMI ${ }^{\mathrm{a}}$} \\
\hline$<25.0$ & $152(46.6)$ \\
\hline $25-29.9$ & $87(26.7)$ \\
\hline$>30.0$ & $87(26.7)$ \\
\hline \multicolumn{2}{|l|}{ Alcohol use ${ }^{\mathrm{a}}$} \\
\hline Never/previous & $170(50.1)$ \\
\hline Current use & $169(49.9)$ \\
\hline \multicolumn{2}{|l|}{ Smoking ${ }^{\mathrm{a}}$} \\
\hline Not now/never & $251(74.9)$ \\
\hline Current use & $84(25.1)$ \\
\hline \multicolumn{2}{|l|}{ Overall stress } \\
\hline$n$, Mean & $325,2.5$ \\
\hline [Minimum-Maximum] & {$[0.0-11.0]$} \\
\hline
\end{tabular}

TABLE 1: Continued.

\begin{tabular}{|c|c|}
\hline & $\begin{array}{c}n(\%) \\
n=341\end{array}$ \\
\hline \multicolumn{2}{|c|}{ Financial stress $^{c}$} \\
\hline Yes & $224(65.7)$ \\
\hline \multicolumn{2}{|c|}{ Emotional stress ${ }^{\mathrm{d}}$} \\
\hline Yes & $100(29.3)$ \\
\hline \multicolumn{2}{|c|}{ Traumatic stress ${ }^{\mathrm{e}}$} \\
\hline Yes & $102(29.9)$ \\
\hline \multicolumn{2}{|c|}{ Partner-Associated stress ${ }^{f}$} \\
\hline Yes & $169(49.6)$ \\
\hline \multicolumn{2}{|c|}{$\begin{array}{l}\text { Abbreviations: BF: breastfeeding; BMI: Body mass index. } \\
\text { a } n<341 \text {. } \\
\text { b Defined using } 9 \text { urban zip codes with elevated levels of poverty. } \\
\text { 'Financial stress defined as answering yes to one of the following occurring } \\
\text { during or in the month after pregnancy: big problems with money, moved } \\
\text { to a new address. } \\
\text { d Emotional stress defined as answering yes to one of the following occurring } \\
\text { during or in the month after pregnancy: family member had serious acci- } \\
\text { dent/illness, husband/partner had serious accident/illness, husband/partner } \\
\text { died, friend/relative died. } \\
\text { eTraumatic stress defined as answering yes to one of the following occurring } \\
\text { during or in the month after pregnancy: stayed in a shelter or needed } \\
\text { emergency shelter, physical fights with partner/husband or someone else, } \\
\text { husband/partner had legal trouble and/or went to jail, mother had legal } \\
\text { trouble and/or went to jail, someone very close had a problem with drinking } \\
\text { or drugs. } \\
\text { fPartner-Associated stress defined as answering yes to one of the following } \\
\text { occurring during or in the month after pregnancy: separated from hus- } \\
\text { band/partner, argued with husband/partner more often, husband/partner } \\
\text { said he did not want pregnancy. }\end{array}$} \\
\hline
\end{tabular}

inner-city residence (as defined by 9 urban zip codes with elevated levels of poverty, locally referenced to as "The Crescent") $[11,12,14]$, breastfeeding factors (prior experience and prenatal plan) $[15,18,21]$, and maternal characteristics (prepregnancy BMI score, self-reported depression during or right after most recent pregnancy, alcohol use, and smoking habits) $[13,16-20]$. No sample size calculation was undertaken since this was a secondary analysis of a convenience sample. All analyses were conducted using SPSS version 19 with a 2 -sided $P$ value set at $<0.05$. Approval for these analyses was obtained from the University of Rochester's IRB.

\section{Results}

Over the two years, $21.0 \%$ of all eligible mothers responded ( $n=760$ ), of which 499 completed the modified survey with 341 reporting ever breastfeeding. As depicted in Table 1 these mothers had a mean age of 26.3 and were primarily Black race (39.6\%), spoke only English at home (70.6\%), had a high school education or more $(74.5 \%)$, and resided within the inner-city $(64.5 \%)$. Other maternal factors included having a breastfeeding plan of 4 or more months (55.9\%), being primiparous $(46.0 \%)$, self-reporting no depression during 
TABLE 2: Breastfeeding cessation outcomes across maternal stress categories $(n=341)$.

\begin{tabular}{|c|c|c|c|c|c|c|c|c|}
\hline & \multicolumn{8}{|c|}{ Categories of stress experienced } \\
\hline & \multicolumn{2}{|c|}{ Financial $^{\mathrm{a}}$} & \multicolumn{2}{|c|}{ Emotional $^{\mathrm{b}}$} & \multicolumn{2}{|c|}{ Traumatic $^{\mathrm{c}}$} & \multicolumn{2}{|c|}{ Partner-Associated $^{\mathrm{d}}$} \\
\hline & $\begin{array}{c}\text { Yes } \\
n=224 \\
n(\%)\end{array}$ & $\begin{array}{c}\text { No } \\
n=115 \\
n(\%)\end{array}$ & $\begin{array}{c}\text { Yes } \\
n=100 \\
n(\%)\end{array}$ & $\begin{array}{c}\text { No } \\
n=231 \\
n(\%)\end{array}$ & $\begin{array}{c}\text { Yes } \\
n=102 \\
n(\%)\end{array}$ & $\begin{array}{c}\text { No } \\
n=233 \\
n(\%)\end{array}$ & $\begin{array}{c}\text { Yes } \\
n=169 \\
n(\%)\end{array}$ & $\begin{array}{c}\text { No } \\
n=172 \\
n(\%)\end{array}$ \\
\hline \multicolumn{9}{|c|}{ Cessation of any BF } \\
\hline by 4 Weeks & $58(25.9)$ & $16(13.9)$ & $20(20.0)$ & $52(22.5)$ & $26(25.5)$ & $46(19.7)$ & $46(27.2)$ & $28(16.3)$ \\
\hline by 13 Weeks & $126(56.3)$ & $64(55.7)$ & $60(60.0)$ & $125(54.1)$ & $61(59.8)$ & $125(53.6)$ & $107(63.3)$ & $83(48.3)$ \\
\hline \multicolumn{9}{|c|}{ Cessation of exclusive $\mathrm{BF}^{\mathrm{e}}$} \\
\hline by 4 Weeks & $157(70.1)$ & $70(60.9)$ & $70(70.0)$ & $151(65.4)$ & $76(74.5)$ & $148(63.5)$ & $121(71.6)$ & $107(62.2)$ \\
\hline by 13 Weeks & $191(85.3)$ & $90(78.3)$ & $83(83.0)$ & $190(82.3)$ & $95(93.1)$ & $182(78.1)$ & $151(89.3)$ & $131(76.2)$ \\
\hline
\end{tabular}

Abbreviations: BF: breastfeeding.

${ }^{a}$ Financial stress defined as answering yes to one of the following occurring during or in the month after pregnancy: big problems with money, moved to a new address. (missing data from 2 mothers).

${ }^{b}$ Emotional stress defined as answering yes to one of the following occurring during or in the month after pregnancy: family member had serious accident/illness, husband/partner had serious accident/illness, husband/partner died, friend/relative died (missing data from 10 mothers).

${ }^{\mathrm{c}}$ Traumatic stress defined as answering yes to one of the following occurring during or in the month after pregnancy: stayed in a shelter or needed emergency shelter, physical fights with partner/husband or someone else, husband/partner had legal trouble and/or went to jail, mother had legal trouble and/or went to jail, someone very close had a problem with drinking or drugs (missing data from 6 mothers).

d Partner-Associated stress defined as answering yes to one of the following occurring during or in the month after pregnancy: separated from husband/partner, argued with husband/partner more often, husband/partner said he did not want pregnancy (missing data from 0 mothers).

${ }^{e}$ Breastfeeding exclusivity was defined as the infant receiving only breast milk and no other liquid or solid food. This calculated outcome was based on mothers self-report of length of breastfeeding (infant age when last received breastmilk) and age when the infant first received formula, other liquids cereal, or solid foods.

or right after most recent pregnancy $(73.6 \%)$, having a prepregnancy BMI score of less than 25.0 (46.6\%), currently using alcohol (49.9\%), and currently smoking (25.1\%). Out of the 14 identified stressful life events, the average number of events experienced during or in the month after pregnancy was 2.5 (range: $0-14$ ).

When broken down by the four stress categories, the most common reported life stress was financial 65.7\% $(n=$ 224). Partner-associated stress followed at $49.6 \%(n=169)$ with traumatic and emotional at $29.9 \%(n=102)$ and $29.3 \%$ $(n=100)$, respectively.

As indicated on Table 2, among those initiating breastfeeding, across the four stress categories breastfeeding cessation rates were similar; within each stress type, a larger proportion of mothers experiencing stress stopped any and exclusive breastfeeding compared with mothers who did not report that type of stress. For example, the proportion of mothers who experienced financial stress who had stopped any BF by 4 weeks was $25.9 \%$ compared to $13.9 \%$ among mothers who did not report financial stress. Comparable numbers were found in the two of the other categories (partner associated: $25.5 \%$ versus $19.7 \%$; traumatic: $27.2 \%$ versus $16.3 \%$ ) but not for emotional where cessation was higher among those not reporting this type of stress $(20.0 \%$ versus $22.5 \%$ ). For the three other breastfeeding cessation outcomes, mothers experiencing all stress types were more likely to have stopped. Cessation of any breastfeeding by 13 weeks among mothers who experienced stress ranged across stress categories from $63.3 \%$ to $48.3 \%$. For cessation of exclusive breastfeeding by 4 weeks among mothers reporting stress, the proportions ranged from $74.5 \%$ to $60.9 \%$ and for those reporting cessation by 13 weeks the range was $93.1 \%$ to $76.2 \%$.

As shown in Table 3, crude analyses comparing the 4 different life stress categories and the 4 breastfeeding cessation outcomes result in odds ratios $(\mathrm{OR})>1.0$ in all but 1 of the 16 comparisons; experiencing emotional stress during or in the month after pregnancy was not a risk factor for cessation of any breastfeeding by 4 weeks. Five relationships were statistically significant: financial stress and duration at 4 weeks $(\mathrm{OR}=2.26$; $95 \% \mathrm{CI}$ : 1.16, 4.40); traumatic stress and exclusivity at both 4 and 13 weeks $(\mathrm{OR}=1.86 ; 95 \%$ CI: $1.07,3.25$; OR $=3.94 ; 95 \%$ CI: 1.61 , 9.61, resp.), and at 13 weeks partner-associated stress with both duration and exclusivity ( $\mathrm{OR}=1.82$; 95\% CI: 1.15, 2.88; $\mathrm{OR}=2.80 ; 95 \%$ CI: 1.46, 5.37, resp.). Consistent with the findings in Table 2, all significant relationships indicated that in each category of life stress those experiencing the stress were more likely to stop breastfeeding.

As shown in Table 4, we conducted 16 different logistic regression models to analyze the relationship between each of the 4 stress categories and the 4 breastfeeding cessation outcomes while adjusting for maternal factors identified a priori. After these adjustments, significant associations remained for only two relationships.

Among low income mothers who initiated breastfeeding, those experiencing financial stress were nearly three times more likely to have stopped any breastfeeding at 4 weeks $(\mathrm{OR}=2.76 ; 95 \% \mathrm{CI}: 1.25,6.06)$. In addition those who planned to breastfeed longer and were high school educated were also at higher risk to stop any breastfeeding by 4 weeks $(\mathrm{OR}=2.89 ; 95 \% \mathrm{CI}: 1.52,5.50$; OR $=2.54 ; 95 \% \mathrm{CI}: 1.14$, 
TABLE 3: Comparison of stress categories and breastfeeding outcomes modeling for breastfeeding cessation.

\begin{tabular}{|c|c|c|c|c|c|c|c|c|}
\hline & \multicolumn{2}{|c|}{$\begin{array}{l}\text { Cessation of any BF } \\
\text { by } 4 \text { weeks }\end{array}$} & \multicolumn{2}{|c|}{$\begin{array}{l}\text { Cessation of any BF } \\
\text { by } 13 \text { weeks }\end{array}$} & \multicolumn{2}{|c|}{$\begin{array}{c}\text { Cessation of exclusive }{ }^{\mathrm{e}} \mathrm{BF} \\
\text { by } 4 \text { weeks }\end{array}$} & \multicolumn{2}{|c|}{$\begin{array}{c}\text { Cessation of exclusive } \text { e }^{\mathrm{B} F} \\
\text { by } 13 \text { weeks }\end{array}$} \\
\hline & OR (95\% CI) & $P$ value & OR (95\% CI) & $P$ value & OR (95\% CI) & $P$ value & OR (95\% CI) & $P$ value \\
\hline Financial stress ${ }^{\mathrm{a}}$ & & 0.02 & & 0.68 & & 0.13 & & 0.17 \\
\hline Yes & $2.26(1.16,4.40)$ & & $1.11(0.68,1.80)$ & & $1.47(0.89,2.43)$ & & $1.55(0.32,2.89)$ & \\
\hline $\begin{array}{l}\text { Emotional } \\
\text { stress }^{\mathrm{b}}\end{array}$ & & 0.34 & & 0.30 & & 0.32 & & 0.79 \\
\hline Yes & $0.73(0.38,1.39)$ & & $1.31(1.79,2.18)$ & & $1.32(0.77,2.28)$ & & $1.10(0.56,2.15)$ & \\
\hline $\begin{array}{l}\text { Traumatic } \\
\text { stress }^{c}\end{array}$ & & 0.29 & & 0.16 & & 0.03 & & $<0.01$ \\
\hline Yes & $1.38(0.76,2.48)$ & & $1.43(0.86,2.36)$ & & $1.86(1.07,3.25)$ & & $3.94(1.61,9.61)$ & \\
\hline $\begin{array}{l}\text { Partner- } \\
\text { Associated } \\
\text { stress }^{\mathrm{d}}\end{array}$ & & 0.06 & & 0.01 & & 0.10 & & $<0.01$ \\
\hline Yes & $1.73(0.98,3.04)$ & & $1.82(1.15,2.88)$ & & $1.50(0.92,2.42)$ & & $2.80(1.46,5.37)$ & \\
\hline
\end{tabular}

Note: Reference is "no" for all 4 types of stress. Modeling for breastfeeding cessation. OR score $1<$ indicates more likely to breastfeed; OR score $1>$ indicates less likely to breastfeed.

Abbreviations: BF: breastfeeding.

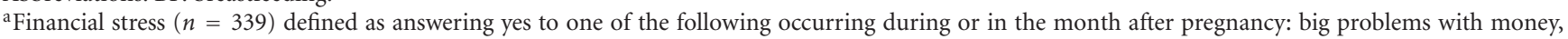
moved to a new address.

${ }^{b}$ Emotional stress $(n=331)$ defined as answering yes to one of the following occurring during or in the month after pregnancy: family member had serious accident/illness, husband/partner had serious accident/illness, husband/partner died, friend/relative died.

${ }^{c}$ Traumatic stress $(n=335)$ defined as answering yes to one of the following occurring during or in the month after pregnancy: stayed in a shelter or needed emergency shelter, physical fights with partner/husband or someone else, husband/partner had legal trouble and/or went to jail, mother had legal trouble and/or went to jail, someone very close had a problem with drinking or drugs.

dPartner-Associated stress $(n=341)$ defined as answering yes to one of the following occurring during or in the month after pregnancy: separated from husband/partner, argued with husband/partner more often, husband/partner said he did not want pregnancy.

${ }^{\mathrm{e}}$ Breastfeeding exclusivity was defined as the infant receiving only breast milk and no other liquid or solid food. This calculated outcome was based on mothers self-report of length of breastfeeding (infant age when last received breastmilk) and age when the infant first received formula, other liquids cereal, or solid foods.

5.64, resp.). Financial stress was not significantly associated with any of the other breastfeeding outcomes although BF plan remained significant as it was in all of the 16 models.

The second model that showed a significant relationship to breastfeeding outcomes was traumatic stress. It was associated with cessation of exclusive breastfeeding by 13 weeks $(\mathrm{OR}=2.95 ; 95 \% \mathrm{CI}: 1.04,8.38)$. Mothers with longer breastfeeding plans were also at higher risk for cessation $(\mathrm{OR}=12.50 ; 95 \% \mathrm{CI}: 4.03,38.77)$, although this should be interpreted with caution given the wide confidence interval. Traumatic stress was not significantly associated with any of the other breastfeeding outcomes.

While controlling for stress, several maternal factors were found to decrease the likelihood of early cessation. These included depression and cessation by 13 weeks in all four of the different stress type models (financial: $\mathrm{OR}=0.38 ; 95 \%$ CI: $0.19,0.75$; emotional: $\mathrm{OR}=0.45 ; 95 \%$ CI: $0.23,0.88$; traumatic: $\mathrm{OR}=0.38$; 95\% CI: $0.19,0.76$; partner associated: OR $=0.46$; 95\% CI: 0.24, 0.92). Current alcohol use and/or smoking use were also protective factors for cessation of any breastfeeding by 13 weeks in all but the financial stress model (emotional: alcohol use: $\mathrm{OR}=0.66 ; 95 \% \mathrm{CI}: 0.46,0.95$; smoking: $\mathrm{OR}=0.37 ; 95 \% \mathrm{CI}$ : 0.17, 0.76; traumatic: smoking: $\mathrm{OR}=0.37 ; 95 \% \mathrm{CI}: 0.18,0.77$; partner associated: smoking: $\mathrm{OR}=0.37 ; 95 \% \mathrm{CI}: 0.18,0.77)$.
For the exclusivity models, while stress was not significant at 4 weeks cessation, higher BMI (>30.0) was also protective in all but financial stress (emotional: $\mathrm{OR}=0.37$; 95\% CI: 0.17, 0.77; traumatic: OR = 0.40; 95\% CI: 0.19, 0.83; partner associated: $\mathrm{OR}=0.38 ; 95 \% \mathrm{CI}: 0.18,0.80)$. Similarly being of Black race also reduced the likelihood of cessation of exclusive breastfeeding by 13 weeks in both the financial and emotional stress models ( $\mathrm{OR}=0.21 ; 95 \% \mathrm{CI}$ : 0.08, 0.57; $\mathrm{OR}=0.23 ; 95 \% \mathrm{CI}: 0.09,0.61)$.

\section{Discussion}

Among a convenience sample of over 340 low-income, primarily urban-dwelling mothers who initiated breastfeeding, not surprisingly over half reported financial stress and nearly half reported partner-associated stress. Across all four types, stress was associated with earlier cessation of any and exclusive breastfeeding. Crude relationships in three of the four stress categories had at least one statistically significant association with breastfeeding cessation. Once adjusted for other maternal factors (e.g., breastfeeding plan, depression, smoking, and alcohol use), the only significant relationships with breastfeeding outcomes were for mothers reporting financial or traumatic stress. Impact of stress on breastfeeding may differ by type of stress. 
TABLE 4: Stress logistic regression for breastfeeding duration and exclusivity outcomes modeling for breastfeeding cessation.

\begin{tabular}{|c|c|c|c|c|c|c|c|c|}
\hline & \multicolumn{2}{|c|}{$\begin{array}{l}\text { Cessation of any BF } \\
\text { by } 4 \text { Weeks }\end{array}$} & \multicolumn{2}{|c|}{$\begin{array}{c}\text { Cessation of any BF } \\
\text { by } 13 \text { Weeks }\end{array}$} & \multicolumn{2}{|c|}{$\begin{array}{l}\text { Cessation of Exclusive }{ }^{\mathrm{g}} \mathrm{BF} \\
\text { by } 4 \text { Weeks }\end{array}$} & \multicolumn{2}{|c|}{$\begin{array}{c}\text { Cessation of Exclusives } \mathrm{BF} \\
\text { by } 13 \text { Weeks }\end{array}$} \\
\hline & OR (95\% CI) & $P$-value ${ }^{\mathrm{a}}$ & OR $(95 \% \mathrm{CI})$ & $P$-value ${ }^{\mathrm{a}}$ & OR (95\% CI) & $P$-value ${ }^{\mathrm{a}}$ & OR $(95 \% \mathrm{CI})$ & $P$-value ${ }^{\mathrm{a}}$ \\
\hline \multicolumn{9}{|l|}{$\begin{array}{l}\text { Financial Stress }{ }^{\mathrm{b}} n= \\
298 \text { [Reference] }\end{array}$} \\
\hline Financial Stress [No] & & 0.02 & & 0.29 & & 0.18 & & 0.80 \\
\hline Yes & $\begin{array}{l}2.76(1.25 \\
\quad 6.06)\end{array}$ & & $\begin{array}{l}0.70(0.36 \\
1.35)\end{array}$ & & $\begin{array}{l}1.51(0.82 \\
2.78)\end{array}$ & & $\begin{array}{l}1.11(0.51 \\
2.42)\end{array}$ & \\
\hline $\begin{array}{l}\text { Race/Ethnicity } \\
\text { [White] }\end{array}$ & & NS & & NS & & NS & & 0.02 \\
\hline Black & - & & - & & - & & $\begin{array}{l}0.21(0.08 \\
\quad 0.57)\end{array}$ & \\
\hline Hispanic & - & & - & & - & & $\begin{array}{l}0.41(0.12 \\
\quad 1.41)\end{array}$ & \\
\hline Mixed/Other & - & & - & & - & & $\begin{array}{l}0.33(0.08 \\
1.39)\end{array}$ & \\
\hline $\begin{array}{l}\text { Education }[<\text { High } \\
\text { School }]\end{array}$ & & 0.04 & & NS & & NS & & NS \\
\hline Unknown & $\begin{array}{l}4.21(0.85 \\
20.83)\end{array}$ & & - & & - & & - & \\
\hline$\geq$ High School & $\begin{array}{l}2.54(1.14 \\
5.64)\end{array}$ & & - & & - & & - & \\
\hline $\begin{array}{l}\text { Breastfeeding Plan } \\
\text { [None/Unknown/Up } \\
\text { to } 3 \text { months] }\end{array}$ & & $<0.01$ & & $<0.01$ & & $<0.01$ & & $<0.01$ \\
\hline 4+ Months & $\begin{array}{l}2.89(1.52 \\
5.50)\end{array}$ & & $\begin{array}{l}6.80(3.71 \\
12.46)\end{array}$ & & $\begin{array}{l}4.94(2.65 \\
\quad 9.24)\end{array}$ & & $\begin{array}{l}10.91(3.54 \\
33.66)\end{array}$ & \\
\hline Depression $^{c}[\mathrm{No}]$ & & NS & & $<0.01$ & & NS & & NS \\
\hline Yes & - & & $\begin{array}{l}0.38(0.19 \\
0.75)\end{array}$ & & - & & - & \\
\hline BMI $[<25.0]$ & & NS & & NS & & 0.01 & & NS \\
\hline $25.0-29.0$ & - & & - & & $\begin{array}{l}1.13(0.58 \\
2.18)\end{array}$ & & - & \\
\hline$>30.0$ & - & & - & & $\begin{array}{l}0.36(0.17 \\
0.77)\end{array}$ & & - & \\
\hline \multicolumn{9}{|l|}{$\begin{array}{l}\text { Emotional Stress }^{\mathrm{d}} n= \\
291 \text { [Reference] }\end{array}$} \\
\hline Emotional Stress [No] & & 0.11 & & 0.91 & & 0.53 & & 0.79 \\
\hline Yes & $\begin{array}{l}0.56(0.27 \\
1.14)\end{array}$ & & $\begin{array}{l}1.04(0.54 \\
1.99)\end{array}$ & & $\begin{array}{l}1.23(0.65 \\
2.33)\end{array}$ & & $\begin{array}{l}0.89(0.38 \\
2.09)\end{array}$ & \\
\hline $\begin{array}{l}\text { Race/Ethnicity } \\
\text { [White] }\end{array}$ & & NS & & NS & & NS & & 0.22 \\
\hline Black & - & & - & & - & & $\begin{array}{l}0.23(0.09 \\
0.61)\end{array}$ & \\
\hline Hispanic & - & & - & & - & & $\begin{array}{l}0.41(0.12 \\
\quad 1.45)\end{array}$ & \\
\hline Mixed/Other & - & & - & & - & & $\begin{array}{l}0.26(0.06 \\
1.22)\end{array}$ & \\
\hline $\begin{array}{l}\text { Breastfeeding Plan } \\
\text { [None/Unknown/Up } \\
\text { to } 3 \text { months] }\end{array}$ & & $<0.01$ & & $<0.01$ & & $<0.01$ & & $<0.01$ \\
\hline 4+ Months & $\begin{array}{l}2.82(1.48 \\
5.39)\end{array}$ & & $\begin{array}{l}6.65(3.60 \\
12.29)\end{array}$ & & $\begin{array}{c}4.56(2.44, \\
8.52)\end{array}$ & & $\begin{array}{c}10.60(3.45 \\
32.63)\end{array}$ & \\
\hline
\end{tabular}


Table 4: Continued.

\begin{tabular}{|c|c|c|c|c|c|c|c|c|}
\hline & \multicolumn{2}{|c|}{$\begin{array}{l}\text { Cessation of any BF } \\
\text { by } 4 \text { Weeks }\end{array}$} & \multicolumn{2}{|c|}{$\begin{array}{l}\text { Cessation of any BF } \\
\text { by } 13 \text { Weeks }\end{array}$} & \multicolumn{2}{|c|}{$\begin{array}{c}\text { Cessation of Exclusive }{ }^{\mathrm{g}} \text { BF } \\
\text { by } 4 \text { Weeks }\end{array}$} & \multicolumn{2}{|c|}{$\begin{array}{c}\text { Cessation of Exclusives } \mathrm{BF} \\
\text { by } 13 \text { Weeks }\end{array}$} \\
\hline & OR $(95 \% \mathrm{CI})$ & $P$-value ${ }^{\mathrm{a}}$ & OR (95\% CI) & $P$-value ${ }^{\mathrm{a}}$ & OR $(95 \% \mathrm{CI})$ & $P$-value ${ }^{\mathrm{a}}$ & OR $(95 \% \mathrm{CI})$ & $P$-value ${ }^{\mathrm{a}}$ \\
\hline $\operatorname{Depression}^{\mathrm{c}}[\mathrm{No}]$ & & NS & & 0.02 & & NS & & NS \\
\hline Yes & - & & $\begin{array}{c}0.45 \\
(0.23-0.88)\end{array}$ & & - & & & \\
\hline BMI $[<25.0]$ & & NS & & NS & & 0.02 & & NS \\
\hline $25.0-29.0$ & - & & - & & $\begin{array}{l}1.03(0.52 \\
2.01)\end{array}$ & & - & \\
\hline$>30.0$ & - & & - & & $\begin{array}{l}0.37(0.17 \\
0.77)\end{array}$ & & - & \\
\hline $\begin{array}{l}\text { Alcohol Use } \\
{[\text { Never/Not Now }]}\end{array}$ & & NS & & 0.03 & & NS & & NS \\
\hline Current Use & - & & $\begin{array}{l}0.66(0.46 \\
0.95)\end{array}$ & & - & & - & \\
\hline $\begin{array}{l}\text { Smoking [Never/Not } \\
\text { Now] }\end{array}$ & & NS & & $<0.01$ & & NS & & NS \\
\hline Current Use & - & & $\begin{array}{l}0.37(0.17 \\
0.76) \\
\end{array}$ & & - & & - & \\
\hline \multicolumn{9}{|l|}{$\begin{array}{l}\text { Traumatic Stress } \\
n=295 \text { [Reference] }\end{array}$} \\
\hline Traumatic Stress [No] & & 0.71 & & 0.61 & & 0.17 & & 0.04 \\
\hline Yes & $\begin{array}{l}1.14(0.57 \\
2.27)\end{array}$ & & $\begin{array}{l}0.84(0.43 \\
1.64)\end{array}$ & & $\begin{array}{l}1.59(0.82 \\
3.12)\end{array}$ & & $\begin{array}{l}2.95(1.04 \\
\quad 8.38)\end{array}$ & \\
\hline Mom Age & & NS & & 0.04 & & NS & & NS \\
\hline Continuous & - & & $\begin{array}{c}1.07(1.00 \\
1.13)\end{array}$ & & - & & & \\
\hline $\begin{array}{l}\text { Breastfeeding Plan } \\
\text { [None/Unknown/Up } \\
\text { to } 3 \text { months] }\end{array}$ & & $<0.01$ & & $<0.01$ & & $<0.01$ & & $<0.01$ \\
\hline 4+ Months & $\begin{array}{l}2.66(1.41 \\
5.01)\end{array}$ & & $\begin{array}{l}7.24(3.92 \\
13.39)\end{array}$ & & $\begin{array}{l}5.24(2.78 \\
\quad 9.85)\end{array}$ & & $\begin{array}{l}12.50(4.03 \\
38.77)\end{array}$ & \\
\hline Depression $^{\mathrm{c}}[\mathrm{No}]$ & & NS & & $<0.01$ & & NS & & NS \\
\hline Yes & - & & $\begin{array}{l}0.38(0.19 \\
0.76)\end{array}$ & & - & & - & \\
\hline BMI $[<25.0]$ & & NS & & NS & & 0.02 & & NS \\
\hline $25.0-29.0$ & - & & - & & $\begin{array}{l}1.11(0.57 \\
\quad 2.17)\end{array}$ & & - & \\
\hline$>30.0$ & - & & - & & $\begin{array}{l}0.40(0.19 \\
0.83)\end{array}$ & & - & \\
\hline $\begin{array}{l}\text { Smoking [Never/Not } \\
\text { Now] }\end{array}$ & & NS & & $<0.01$ & & NS & & NS \\
\hline Current Use & - & & $\begin{array}{l}0.37(0.18 \\
0.77) \\
\end{array}$ & & - & & - & \\
\hline \multicolumn{9}{|l|}{$\begin{array}{l}\text { Partner-Associated } \\
\text { Stress }^{f} n=300 \\
{[\text { Reference] }}\end{array}$} \\
\hline $\begin{array}{l}\text { Partner-Associated } \\
\text { Stress [No] }\end{array}$ & & 0.11 & & 0.30 & & 0.79 & & 0.11 \\
\hline Yes & $\begin{array}{l}1.71(0.88 \\
3.30) \\
\end{array}$ & & $\begin{array}{l}1.37(0.76 \\
2.48)\end{array}$ & & $\begin{array}{c}1.08(0.61 \\
1.93)\end{array}$ & & $\begin{array}{l}1.92(0.86 \\
4.31)\end{array}$ & \\
\hline
\end{tabular}


TABle 4: Continued.

\begin{tabular}{|c|c|c|c|c|c|c|c|c|}
\hline & \multicolumn{2}{|c|}{$\begin{array}{l}\text { Cessation of any BF } \\
\text { by } 4 \text { Weeks }\end{array}$} & \multicolumn{2}{|c|}{$\begin{array}{l}\text { Cessation of any BF } \\
\text { by } 13 \text { Weeks }\end{array}$} & \multicolumn{2}{|c|}{$\begin{array}{c}\text { Cessation of Exclusive }{ }^{\mathrm{g}} \mathrm{BF} \\
\text { by } 4 \text { Weeks }\end{array}$} & \multicolumn{2}{|c|}{$\begin{array}{c}\text { Cessation of Exclusive }{ }^{\mathrm{g}} \mathrm{BF} \\
\text { by } 13 \text { Weeks }\end{array}$} \\
\hline & OR (95\% CI) & $P$-value ${ }^{\mathrm{a}}$ & OR (95\% CI) & $P$-value ${ }^{\mathrm{a}}$ & OR (95\% CI) & $P$-value ${ }^{\mathrm{a}}$ & OR $(95 \% \mathrm{CI})$ & $P$-value ${ }^{\mathrm{a}}$ \\
\hline $\begin{array}{l}\text { Education [<High } \\
\text { School] }\end{array}$ & & $<0.05$ & & NS & & NS & & NS \\
\hline Unknown & $\begin{array}{c}3.89(0.77 \\
19.63)\end{array}$ & & - & & - & & - & \\
\hline$\geq$ High School & $\begin{array}{c}2.53(1.14 \\
5.60)\end{array}$ & & - & & - & & - & \\
\hline $\begin{array}{l}\text { Breastfeeding Plan } \\
\text { [None/Unknown/Up } \\
\text { to } 3 \text { months] }\end{array}$ & & $<0.01$ & & $<0.01$ & & $<0.01$ & & $<0.01$ \\
\hline 4+ Months & $\begin{array}{c}2.84(1.51 \\
5.37)\end{array}$ & & $\begin{array}{c}7.39(4.01 \\
13.63)\end{array}$ & & $\begin{array}{l}4.84(2.61 \\
\quad 9.00)\end{array}$ & & $\begin{array}{c}11.46(3.72 \\
35.36)\end{array}$ & \\
\hline Depression $^{c}[\mathrm{No}]$ & & NS & & 0.03 & & $<0.05$ & & NS \\
\hline Yes & - & & $\begin{array}{l}0.46(0.24 \\
0.92)\end{array}$ & & $\begin{array}{c}0.50(0.25 \\
0.99)\end{array}$ & & - & \\
\hline BMI $[<25.0]$ & & NS & & NS & & 0.02 & & NS \\
\hline $25.0-29.0$ & - & & - & & $\begin{array}{l}1.09(0.57, \\
2.11)\end{array}$ & & - & \\
\hline$>30.0$ & - & & - & & $\begin{array}{l}0.38(0.18 \\
0.80)\end{array}$ & & - & \\
\hline $\begin{array}{l}\text { Smoking [Never/Not } \\
\text { Now] }\end{array}$ & & NS & & $<0.01$ & & NS & & NS \\
\hline Current Use & - & & $\begin{array}{c}0.37(0.18 \\
0.77)\end{array}$ & & - & & - & \\
\hline
\end{tabular}

Note: Reference is "no" for all 4 types of stress. Modeling for breastfeeding cessation. OR score $1<$ indicates more likely to breastfeed; OR score $1>$ indicates less likely to breastfeed.

Variables Included in Model: age (continuous), race, language, education, inner-city residence, breastfeeding plan, parity and breastfeeding, depression, BMI, alcohol use, smoking.

Abbreviations: BF: Breastfeeding; NS: not significant.

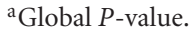

${ }^{b}$ Financial stress defined as answering yes to one of the following occurring during or in the month after pregnancy: big problems with money, moved to a new address.

${ }^{c}$ Self-reported depression during or right after pregnancy.

${ }^{\mathrm{d}}$ Emotional stress defined as answering yes to one of the following occurring during or in the month after pregnancy: family member had serious accident/illness, husband/partner had serious accident/illness, husband/partner died, friend/relative died.

${ }^{\text {e}}$ Traumatic stress defined as answering yes to one of the following occurring during or in the month after pregnancy: stayed in a shelter or needed emergency shelter, physical fights with partner/husband or someone else, husband/partner had legal trouble and/or went to jail, mother had legal trouble and/or went to jail, someone very close had a problem with drinking or drugs.

${ }^{\mathrm{f}}$ Partner-Associated stress defined as answering yes to one of the following occurring during or in the month after pregnancy: separated from husband/partner, argued with husband/partner more often, husband/partner said he did not want pregnancy.

gBreastfeeding exclusivity was defined as the infant receiving only breast milk and no other liquid or solid food. This calculated outcome was based on mothers self-report of length of breastfeeding (infant age when last received breastmilk) and age when the infant first received formula, other liquids cereal, or solid foods.

Despite methodological differences, our findings are consistent with the one breastfeeding and stress analysis by Li et al. (2008). [29]. Their study was from a different country (Australia), and the authors' operationalized stress differently and focused on a heterogeneous rather than only a low-income population. Despite these differences, they also demonstrated a significant relationship between stressful life events and the likelihood of early cessation of breastfeeding.

Other significant relationships in all four models were found with the outcome of cessation of any breastfeeding at 13 weeks. Stressed mothers who were depressed, smoked, and, for emotional stress, used alcohol were less likely to stop breastfeeding. These findings were inconsistent with other studies $[17,20]$. Interestingly depression, alcohol use and smoking were not significant factors in early cessation of any breastfeeding (i.e., 4 weeks), which is consistent with the literature $[16,18,19]$. Mothers may receive breastfeeding support in the early postpartum period that dampens the negative influence of depression, alcohol use, and smoking on breastfeeding. Additionally, alcohol and cigarette use may be mechanisms used by mothers to selfmedicate to help manage stress or depression [33, 34] and hence their protective association with breastfeeding outcomes. 
The relationship between stressful life events and depression is likely complex [33]. While it seems reasonable that mothers experiencing stress would stop breastfeeding earlier, other findings are less intuitive. Mothers reporting depression during pregnancy were less likely to stop any breastfeeding by 13 weeks across all stress categories. However, this finding is consistent with research showing that breastfeeding may buffer negative mood [35] and decrease stress hormone levels [36]. Another study found breastfeeding mothers to be more relaxed compared to bottle feeding mothers [37]. Further it is possible that for low income mothers the association previously identified between depression and breastfeeding outcomes is a proxy for the impact of stress [19]. Finally, while some literature suggests an indirect relationship between postpartum depression and breastfeeding outcomes, further interpretation of this significant relationship in our study is limited as the item used asked about depression during or right after the pregnancy?" (yes/no) and not postpartum depression per se [38, 39].

Plans for longer breastfeeding were significantly and independently associated with earlier cessation of any and exclusive breastfeeding. This differs from other studies where having a specific goal for breastfeeding (e.g., 6 months), considered a proxy for maternal self-efficacy, was associated with delayed cessation of breastfeeding [15, 18, 21]. Stress may mitigate against the mother's ability to achieve her plan. Specific to our findings, a mother planning to breastfeed longer, if she has financial stress may not be able to maintain breastfeeding to achieve her goal. Our findings reaffirm the broad impact that stress may have on breastfeeding selfefficacy.

Black mothers are commonly found to have a lower breastfeeding and exclusivity rates $[11,12]$. While race was included in all 16 models, it was only statistically significant in one (emotional stress and exclusivity at 13 weeks) and it was protective. Other factors associated with race may be stronger predictors, or Black race, as it is used in other analyses, may not be a factor by itself but serve as a proxy for other barriers to sustaining breastfeeding in that subpopulation.

4.1. Limitations. The sample used for this analysis was drawn from a convenience sample of low-income mothers. Due to the relatively small sample, we may not have adequate power to detect statistically significant relationships for some outcomes. It is possible that some of the significant relationships were spurious findings particularly if a factor was a significant predictor at 4 but not at 13 weeks or vice versa. As this was an exploratory analysis, the stress categories did not adjust for the extent to which the respondent experienced physiologic stress (e.g., elevated cortisol levels). Data used in these analyses were self-report and are subject to the biases associated with these types of data. Breastfeeding outcomes assessed within 3 years are considered reliable, and our data collection was well within that timeframe [40]. Additionally our analyses do not account for other factors that may be associated with breastfeeding such as interpersonal support or hospital factors.

\section{Conclusions}

Not all stressful life events may have an impact on cessation of any or exclusive breastfeeding among low-income women. Impact may differ by stress type. Stress may interfere with the achievement of the mother's breastfeeding goal. The association of depression, smoking, and alcohol use on breastfeeding cessation after adjusted for stress may indicate that breastfeeding serves as a coping mechanism. More research is needed to understand the relationship between breastfeeding plan, stress, other maternal factors, and their impact on breastfeeding outcomes.

\section{Acknowledgments}

The authors wish to acknowledge the efforts of Holly Widanka, MA, for her efforts in overseeing the survey administration process. This project was funded through a National Institutes of Health PHS Grant no. RO1HD055191, Community Partnership for Breastfeeding Promotion and Support.

\section{References}

[1] S. Ip, M. Chung, G. Raman et al., "Breastfeeding and maternal and infant health outcomes in developed countries," Evidence Report/Technology Assessment, no. 153, pp. 1-186, 2007.

[2] M. S. Kramer and R. Kakuma, "Optimal duration of exclusive breastfeeding," Cochrane Database of Systematic Reviews, no. 1, Article ID CD003517, 2002.

[3] U. DHHS, Healthy People 2020, Office of Disease Prevention and Health Promotion, 2010.

[4] "Section on Breastfeeding. Breastfeeding and the use of human milk," Pediatrics, vol. 129, no. 3, pp. e827-e841, 2012.

[5] U. DHHS, The Surgeon General's Call to Action to Support Breastfeeding, US DHHS, Office of Surgeon General, Washington, DC, 2011.

[6] "WIC_-breastfeeding promotion and support," 2012, http:// www.fns.usda.gov/wic/breastfeeding/mainpage.HTM.

[7] Healthy people.gov, "Maternal, infant, and child health objectives," 2012, http://www.healthypeople.gov/2020/topicsobjectives2020/objectiveslist.aspx?topicid=26.

[8] E. Difrisco, K. E. Goodman, W. C. Budin, M. W. Lilienthal, A. Kleinman, and B. Holmes, "Factors associated with exclusive breastfeeding 2 to 4 weeks following discharge from a large, urban, academic medical center striving for baby-friendly designation," The Journal of Perinatal Education, vol. 20, no. 1, pp. 28-35, 2011.

[9] B. A. Langellier, M. P. Chaparro, and S. E. Whaley, "Social and institutional factors that affect breastfeeding duration among WIC participants in Los Angeles County, California," Maternal and Child Health Journal, vol. 16, no. 9, pp. 18871895, 2012.

[10] J. E. Shim, J. Kim, and J. B. Heiniger, "Breastfeeding duration in relation to child care arrangement and participation in the special supplemental nutrition program for women, infants, and children," Journal of Human Lactation, vol. 28, no. 1, pp. 28-35, 2012.

[11] J. R. Jones, M. D. Kogan, G. K. Singh, D. L. Dee, and L. M. Grummer-Strawn, "Factors associated with exclusive breastfeeding in the United States," Pediatrics, vol. 128, no. 6, pp. 1117-1125, 2011. 
[12] A. C. Chin, L. Myers, and J. H. Magnus, "Race, education, and breastfeeding initiation in Louisiana, 2000-2004," Journal of Human Lactation, vol. 24, no. 2, pp. 175-185, 2008.

[13] U. J. Mehta, A. M. Siega-Riz, A. H. Herring, L. S. Adair, and M. E. Bentley, "Pregravid body mass index, psychological factors during pregnancy and breastfeeding duration: is there a link?" Maternal and Child Nutrition, vol. 8, no. 4, pp. 423-433, 2012.

[14] M. J. Heinig, J. R. Follett, K. D. Ishii, K. KavanaghProchaska, R. Cohen, and J. Panchula, "Barriers to compliance with infant-feeding recommendations among low-income women," Journal of Human Lactation, vol. 22, no. 1, pp. 27$38,2006$.

[15] S. Meedya, K. Fahy, and A. Kable, "Factors that positively influence breastfeeding duration to 6 months: a literature review," Women and Birth, vol. 23, no. 4, pp. 135-145, 2010.

[16] A. T. Gerd, S. Bergman, J. Dahlgren, J. Roswall, and B. Alm, "Factors associated with discontinuation of breastfeeding before 1 month of age," Acta Paediatrica, vol. 101, no. 1, pp. 55-60, 2012.

[17] T. M. Weiser, M. Lin, V. Garikapaty, R. W. Feyerharm, D. M. Bensyl, and B. P. Zhu, "Association of maternal smoking status with breastfeeding practices: Missouri, 2005," Pediatrics, vol. 124, no. 6, pp. 1603-1610, 2009.

[18] R. G. Chaves, J. A. Lamounier, and C. C. César, "Factors associated with duration of breastfeeding," Jornal de Pediatria, vol. 83, no. 3, pp. 241-246, 2007.

[19] C. L. Dennis and K. McQueen, "The relationship between infant-feeding outcomes and postpartum depression: a qualitative systematic review," Pediatrics, vol. 123, no. 4, pp. e736e751, 2009.

[20] J. R. Pippins, P. Brawarsky, R. A. Jackson, E. Fuentes-Afflick, and J. S. Haas, "Association of breastfeeding with maternal depressive symptoms," Journal of Women's Health, vol. 15, no. 6, pp. 754-762, 2006.

[21] M. L. Johnston and N. Esposito, "Barriers and facilitators for breastfeeding among working women in the United States," Journal of Obstetric, Gynecologic, and Neonatal Nursing, vol. 36, no. 1, pp. 9-20, 2007.

[22] I. B. Ahluwalia, R. Merritt, L. F. Beck, and M. Rogers, "Multiple lifestyle and psychosocial risks and delivery of small for gestational age infants," Obstetrics and Gynecology, vol. 97, no. 5, pp. 649-656, 2001.

[23] A. S. Hosler, S. G. Nayak, and A. M. Radigan, "Stressful events, smoking exposure and other maternal risk factors associated with gestational diabetes mellitus," Paediatric and Perinatal Epidemiology, vol. 25, no. 6, pp. 566-574, 2011.

[24] S. L. Martin, J. M. Griffin, L. L. Kupper, R. Petersen, M. BeckWarden, and P. A. Buescher, "Stressful life events and physical abuse among pregnant women in North Carolina," Maternal and Child Health Journal, vol. 5, no. 3, pp. 145-152, 2001.

[25] S. Nkansah-Amankra, K. J. Luchok, J. R. Hussey, K. Watkins, and X. Liu, "Effects of maternal stress on low birth weight and preterm birth outcomes across neighborhoods of South Carolina, 2000-2003," Maternal and Child Health Journal, vol. 14, no. 2, pp. 215-226, 2010.

[26] N. S. Whitehead, D. J. Brogan, C. Blackmore-Prince, and H. A. Hill, "Correlates of experiencing life events just before or during pregnancy," Journal of Psychosomatic Obstetrics and Gynecology, vol. 24, no. 2, pp. 77-86, 2003.

[27] D. Y. LaCoursiere, K. P. Hirst, and E. Barrett-Connor, "Depression and pregnancy stressors affect the association between abuse and postpartum depression," Maternal and Child Health Journal, vol. 16, no. 4, pp. 929-935, 2012.
[28] O. 'Connor TG, K. Bergman, P. Sarkar, and V. Glover, "Prenatal cortisol exposure predicts infant cortisol response to acute stress," Developmental Psychobiology. In press.

[29] J. Li, G. E. Kendall, S. Henderson, J. Downie, L. Landsborough, and W. H. Oddy, "Maternal psychosocial well-being in pregnancy and breastfeeding duration," Acta Paediatrica, International Journal of Paediatrics, vol. 97, no. 2, pp. 221-225, 2008.

[30] "CDC-pregnancy risk assessment monitoring system-reproductive health," 2012, http://www.cdc.gov/prams/.

[31] G. M. Wagnild and H. M. Young, "Development and psychometric evaluation of the Resilience Scale," Journal of nursing measurement, vol. 1, no. 2, pp. 165-178, 1993.

[32] G. M. Wagnild and H. M. Young, "The 14-item Resilience Scale," 2012, http://www.resiliencescale.com/en/rstest/rstest_ 14_en.html.

[33] A. Bowen, R. Bowen, P. Butt, K. Rahman, and N. Muhaiarine, "Patterns of depression and treatment in pregnant and postpartum women," Canadian Journal of Psychiatry, vol. 57, no. 3, pp. 161-167, 2012.

[34] D. A. Webb, J. F. Culhane, L. Mathew, J. R. Bloch, and R. L. Goldenberg, "Incident smoking during pregnancy and the postpartum period in a low-income urban population," Public Health Reports, vol. 126, no. 1, pp. 50-59, 2011.

[35] E. S. Mezzacappa and E. S. Katkin, "Breast-feeding is associated with reduced perceived stress and negative mood in mothers," Health Psychology, vol. 21, no. 2, pp. 187-193, 2002.

[36] M. T. Tu, S. J. Lupien, and C. D. Walker, "Diurnal salivary cortisol levels in postpartum mothers as a function of infant feeding choice and parity," Psychoneuroendocrinology, vol. 31, no. 7, pp. 812-824, 2006.

[37] T. Field, M. Diego, M. Hernandez-Reif, B. Figueiredo, S. Ezell, and V. Siblalingappa, "Depressed mothers and infants are more relaxed during breastfeeding versus bottlefeeding interactions: brief report," Infant Behavior and Development, vol. 33, no. 2, pp. 241-244, 2010.

[38] J. J. Henderson, S. F. Evans, J. A. Y. Straton, S. R. Priest, and R. Hagan, "Impact of postnatal depression on breastfeeding duration," Birth, vol. 30, no. 3, pp. 175-180, 2003.

[39] S. Watkins, S. Meltzer-Brody, D. Zolnoun, and A. Stuebe, "Early breastfeeding experiences and postpartum depression," Obstetrics and Gynecology, vol. 118, no. 2, part 1, pp. 214-221, 2011.

[40] R. Li, K. S. Scanlon, and M. K. Serdula, "The validity and reliability of maternal recall of breastfeeding practice," Nutrition Reviews, vol. 63, no. 4, pp. 103-110, 2005. 


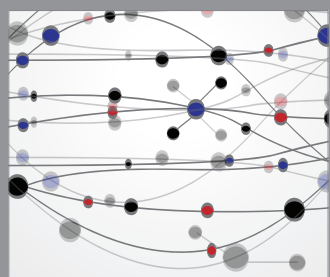

The Scientific World Journal
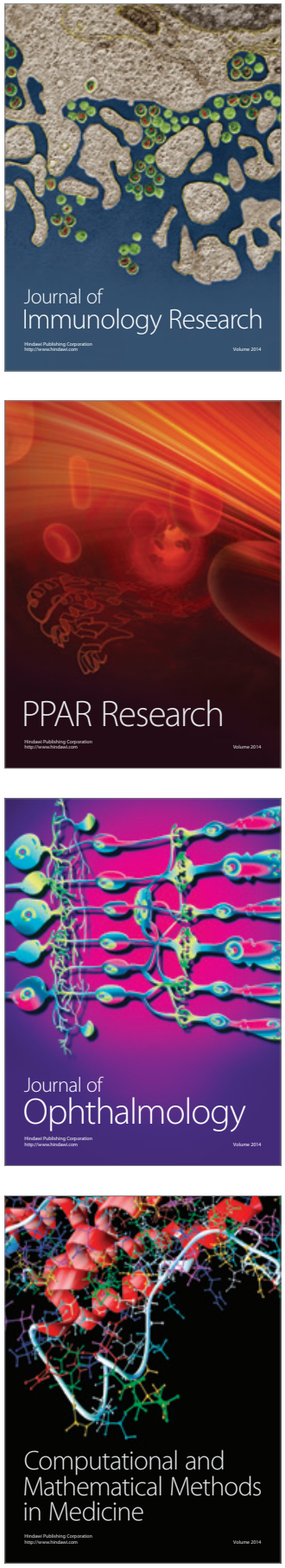

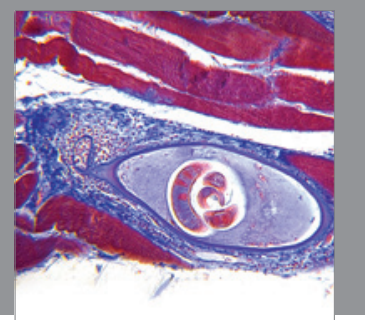

Gastroenterology

Research and Practice
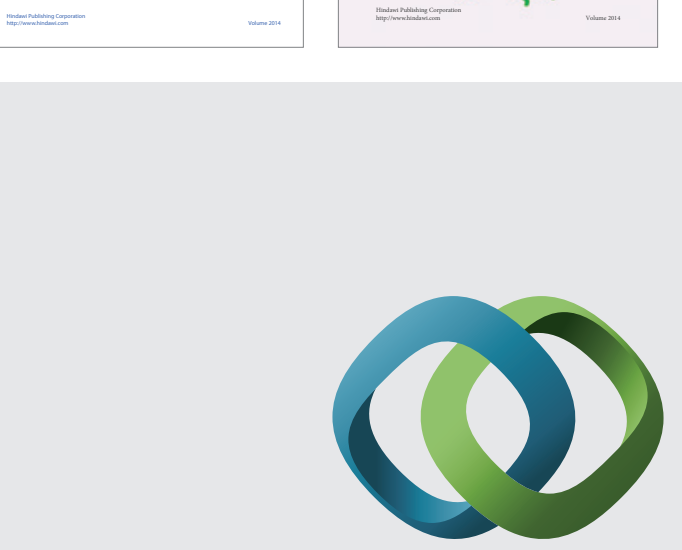

\section{Hindawi}

Submit your manuscripts at

http://www.hindawi.com
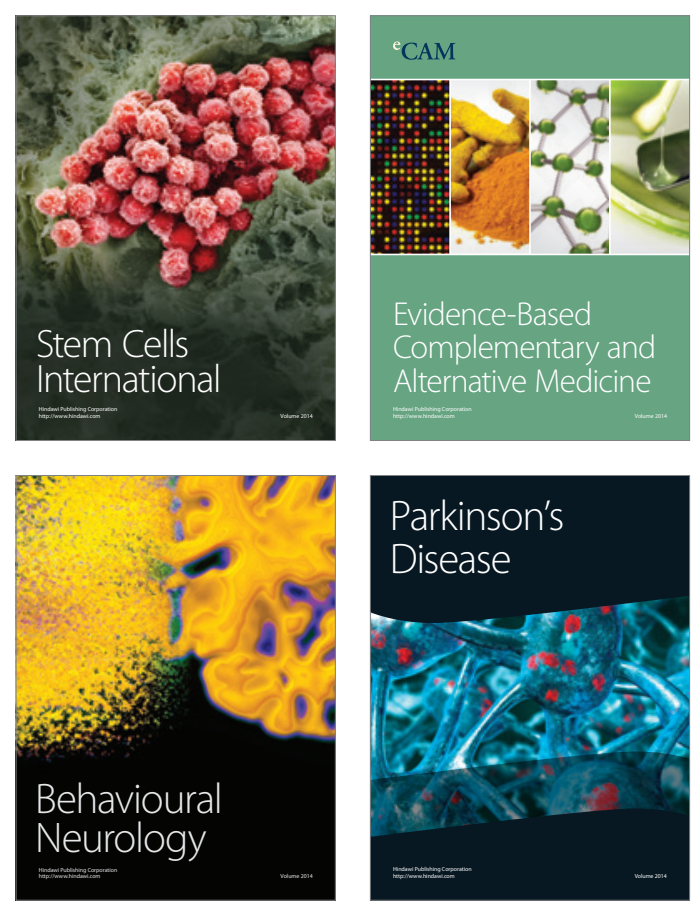

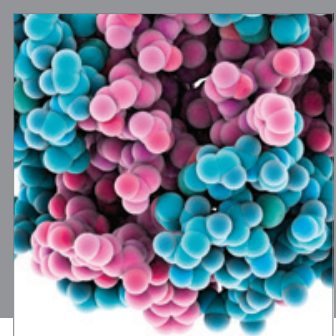

Journal of
Diabetes Research

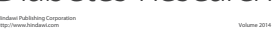

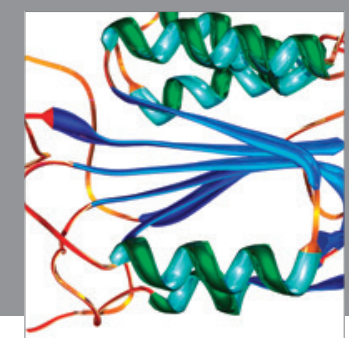

Disease Markers
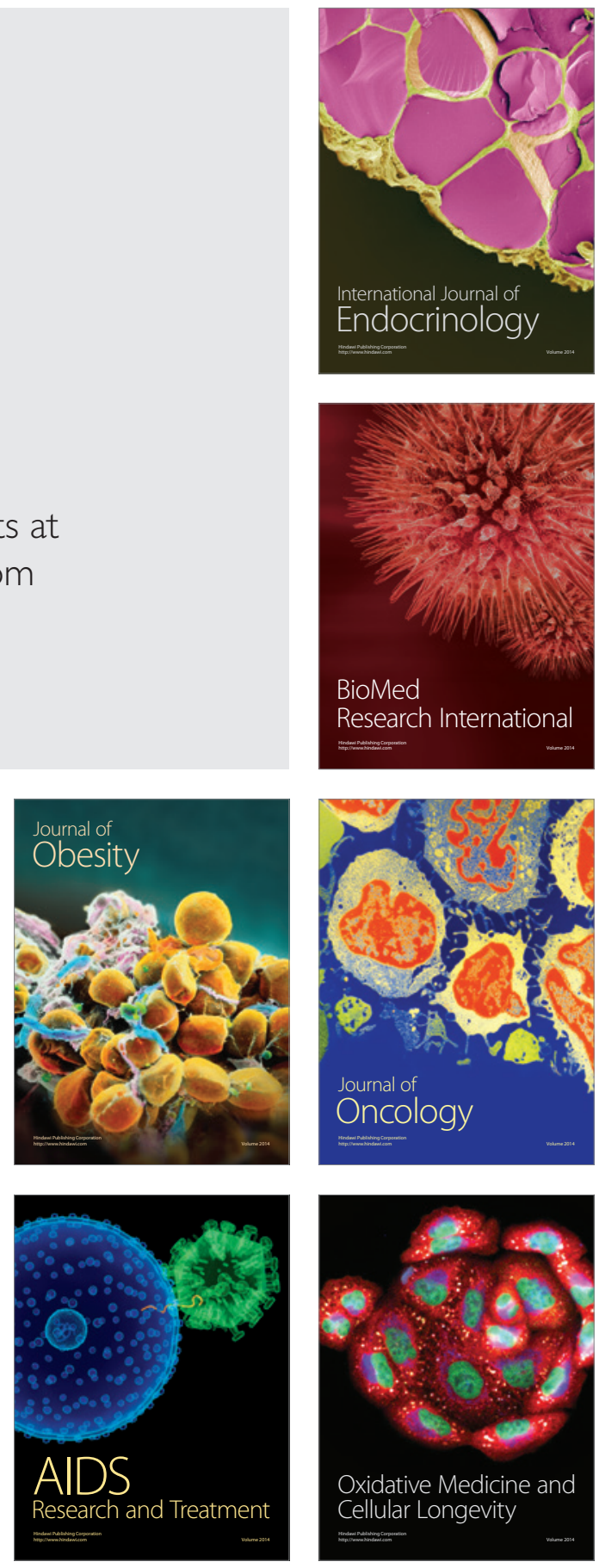